\title{
X-RAY DIFFRACTION STUDY OF RESIDUAL STRESS DISTRIBUTION ON SURFACE OF LASER WELDED STEEL SHEETS
}

\author{
Jiří Čapek, Nikolaj Ganev, Karel Trojan \& Jakub Němeček \\ Faculty of Nuclear Sciences and Physical Engineering, Czech Technical University in Prague \\ Trojanova 13, 12000 Prague 2, Czech Republic \\ phone: +420 224358 624, e-mail: Jiri.Capek@fjfi.cvut.cz
}

\begin{abstract}
Generally, the manufacturing processes of machine component introduce residual stresses (RS) that have an essential influence on their behaviour during service life. The purpose of this study is to evaluate the residual stress distribution of specimens joined by using high power diode laser welding. Non-destructive methods for detection and measurement of RS have been increasingly used in the last few years. The paper outlines the capability of X-ray diffraction (XRD), which can be used for quantitative analysis of macro and micro level RS separately, to describe a state of residual stresses of high pressure welds. The results show from this paper that laser welding has application potential in the welding of high pressure steels.
\end{abstract}

Keywords: laser welding, $X$-ray diffraction, residual stresses, high pressure welds.

\section{INTRODUCTION}

Not only welding using the high power diode lasers (HPDL) is nowadays the standard in many different industrial fields which require precision accuracy and high production efficiency. Therefore, the paper outlines the capability of the advanced laser welding for joining thick sheets of steel for pressure equipment (such as pipelines, pressure vessels, compressor stations, boilers etc.) using X-ray diffraction (XRD). Residual stresses (RS) are the stresses which occur in the material without the action of external forces. Generally, it can be remarked, that mainly high compressive residual stresses could increase yield loads, promote crack initialization and also decelerate its propagation. So it is essential to achieve such a state of residual stress by applying various mechanical and thermal processing, which exhibits favourable residual stresses in critical areas of the component [1]. When deploying this new productive laser welding technology, it is necessary to describe the influence of welding on the real structure and residual stresses. Improve in the results during impact and tensile test and mainly enhance fatigue life is also a result of a favourable distribution of RS in the weld zone and heat affected zone (HAZ), which was for example shown in [2]. It is supposed that high tensile RS due to welding have a strong negative effect on the strength properties, especially fatigue of material under loading. Furthermore, when a welded part with high local RS is machined, the equilibrium state of RS is disturbed, and thus significant distortion may occur. X-ray diffraction is a well-established method for residual stress determination in polycrystalline materials. It is based on measurements of interplanar lattice spacing changes due to acted stress and their conversion to RS using theoretical elasticity equations [1].

Recent practical approaches distinguish between RS due to shrinking process and phase transformation. The shrinkage RS are resulting from the local heating and cooling processes in the weld metal and adjacent HAZ (Fig. 1). Tensile RS around a single pass in a plane sample are expected due to the cool adjacent zones in the base material of the plate. These 


\section{ARTTIE $Y$}

Ipplied Resseirl'hes in Teednicis, Technologies and Bductition

Journal of the Faculty of Technics and Technologies, Trakia University https://sites.google.com/a/trakia-uni.bg/artte/

cold zones are hindering strongly the longitudinal shrinkage of the weld zone where the transverse shrinkage principally is more or less free, i.e. not hindered [3].

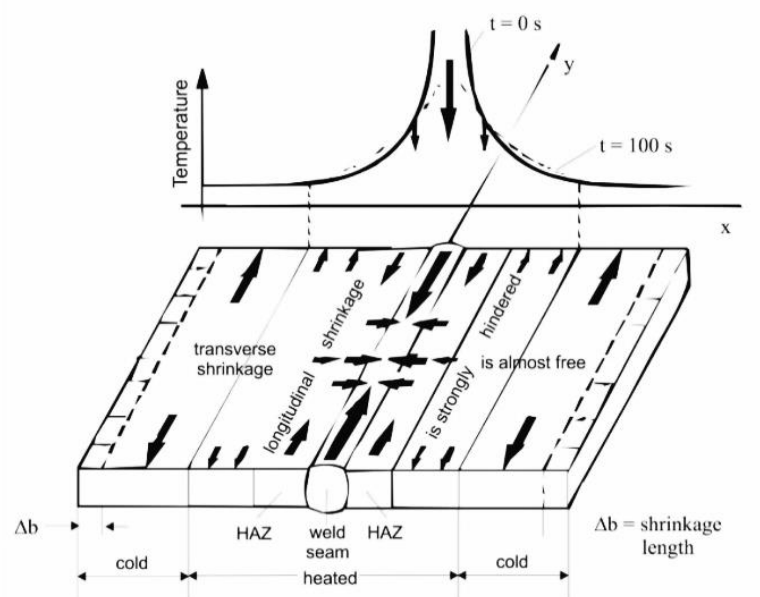

Figure 1. Shrinkage tendency and constraint conditions in a single pass weld (schematically) [3]

However, for complete description of the austenite phase transformation associated with a change in volume, it must be taken into consideration as a significant source of residual stresses especially in high strength steels. The local compressive residual stresses arise in the weld zone as a consequence of the restrained volume expansion during the transformation of austenite in martensite, bainite or ferrite. This effect is caused by the change of the close-packed face-centred cubic (fcc) crystal structure to the body-centred cubic (bcc) crystal structure or body-centred tetragonal (bct), respectively. The resulting distribution of residual stresses is a combined effect of hindered shrinkage and phase transformations [1].

\section{EXPERIMENTAL}

For analyses, three sheets made of P355 (marked as "N") steels each of dimensions $150 \times 300 \mathrm{~mm}^{3}$ were used. The analysed samples were prepared using a HPDL laser. Each sample was marked as follows: "NxLy" where " $x$ " is thickness (i.e. 5, 8 and $10 \mathrm{~mm}$ ), $L$ means "laser weld", and " $y$ " denote side of samples (i.e. "U" - up or "D" - down). Samples with thickness of $5 \mathrm{~mm}$ have single-sided welds, i.e. upper sides were welded. Samples with thickness of 8 and $10 \mathrm{~mm}$ had double-sided welds, where upper sides were welded as first. The measurements were performed on the surfaces of the samples in the three areas, start of weld (S), finish of weld $(F)$ and middle part $(M)$ of sheet plates, in 18 points $(0-30 \mathrm{~mm}$ from the centre of the weld) in the longitudinal (L) and transversal (T) direction, see Fig. 2.

A PROTO IXRD COMBO diffractometer with $\omega$-goniometer set-up was used to measure lattice deformations using manganese radiation. The diffraction lines $\{211\}$ of $\alpha$-Fe phase were analysed for obtaining macroscopic residual stresses. Gaussian function and Absolute peak method were used for determination of the diffraction angles $2 \theta^{211}$ of the diffraction lines $K \alpha_{1}$. For the residual stresses evaluation, $\sin ^{2} \psi$ method with X-ray elastic constants $1 / 2 \mathrm{~S}_{2}=5.76 \mathrm{TPa}^{-1}, \mathrm{~s}_{1}=-1.25 \mathrm{TPa}^{-1}$ was used. A cylinder collimator with diameter of $1 \mathrm{~mm}$ was inserted into the primary beam path. The samples were moving by $\pm 5 \mathrm{~mm}$ in the direction perpendicular with the weld $(\mathrm{L})$, therefore, the irradiated area was approx.

IRTIIE Vol. 5, No. 3, 2017 ISSN 1314-8788 (print), ISSN 1314-8796 (online), doi: 10.15547/artte.2017.03.004 


\section{IRTIIE}

Ipplied Researreches in Technics, Technologies and Bducition Journal of the Faculty of Technics and Technologies, Trakia University https://sites.google.com/a/trakia-uni.bg/artte/

$11 \times 1 \mathrm{~mm}^{2}$. The average value of the effective penetration depth of CrKa radiation into the iron-based material was approx. $5 \mu \mathrm{m}$.

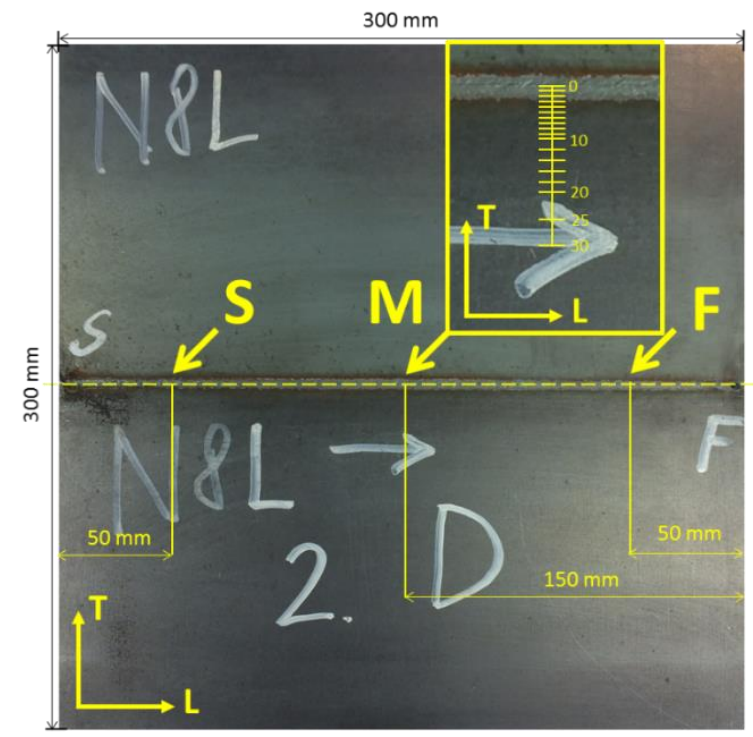

Figure 2. Experimental sample with marked analysed points

\section{RESULTS}

\subsection{Influence of area of the plate (S, M, F)}

In Fig. 3, there are surface residual stresses in relation to analysed area of the sample. It is evident that trends of RS of areas S, M, F are almost identical. Therefore, analysed area does not have influence on RS trends. Due to anisotropic shrinkage during cooling, see Fig. 1, values of tensile $R S$ are higher in the $L$ direction For industry application, the $T$ direction is more important than $L$ direction. In the direction $T$, the favourable compressive RS were analysed in the HAZ. The drop of values of RS is probably caused by phase transition (fcc $\rightarrow$ bcc or bct) in the HAZ (heat affected zone) in the T direction. Stress affected zone (SAZ) is approx. 15-20 mm from the centre of the weld.
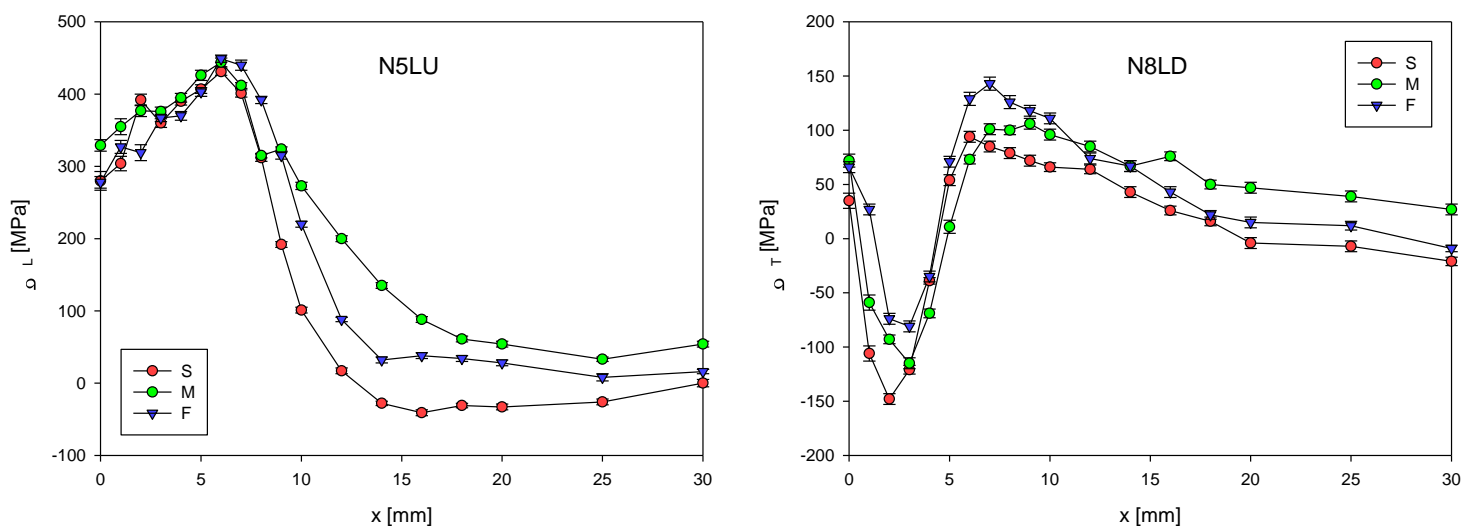

Figure 3. Surface residual stresses in relation to analysed area of the sample; $x$ stands for distance from the weld's centre

IRTIIE Vol. 5, No. 3, 2017 ISSN 1314-8788 (print), ISSN 1314-8796 (online), doi: 10.15547/artte.2017.03.004 


\subsection{Influence of thickness of the plates}

For RS dependence on the thickness of samples, see Figs. 4. The trends of RS are similar for all the thicknesses. Nevertheless, from the results of surface X-ray diffraction measurements, it was found that the thicker samples have narrower HAZ and SAZ about 2 - $3 \mathrm{~mm}$ and $1-2 \mathrm{~mm}$, respectively. On the side $U$, compressive RS increase or tensile RS decrease with increasing thickness in the both directions. The reason of these trends results from larger volume of materials to heat conducting. Therefore, in the case of thicker samples, the high thermal influence is closer to weld. For the side $D$, higher compressive RS were analysed on the surface of HAZ of sample N10 in the direction T.
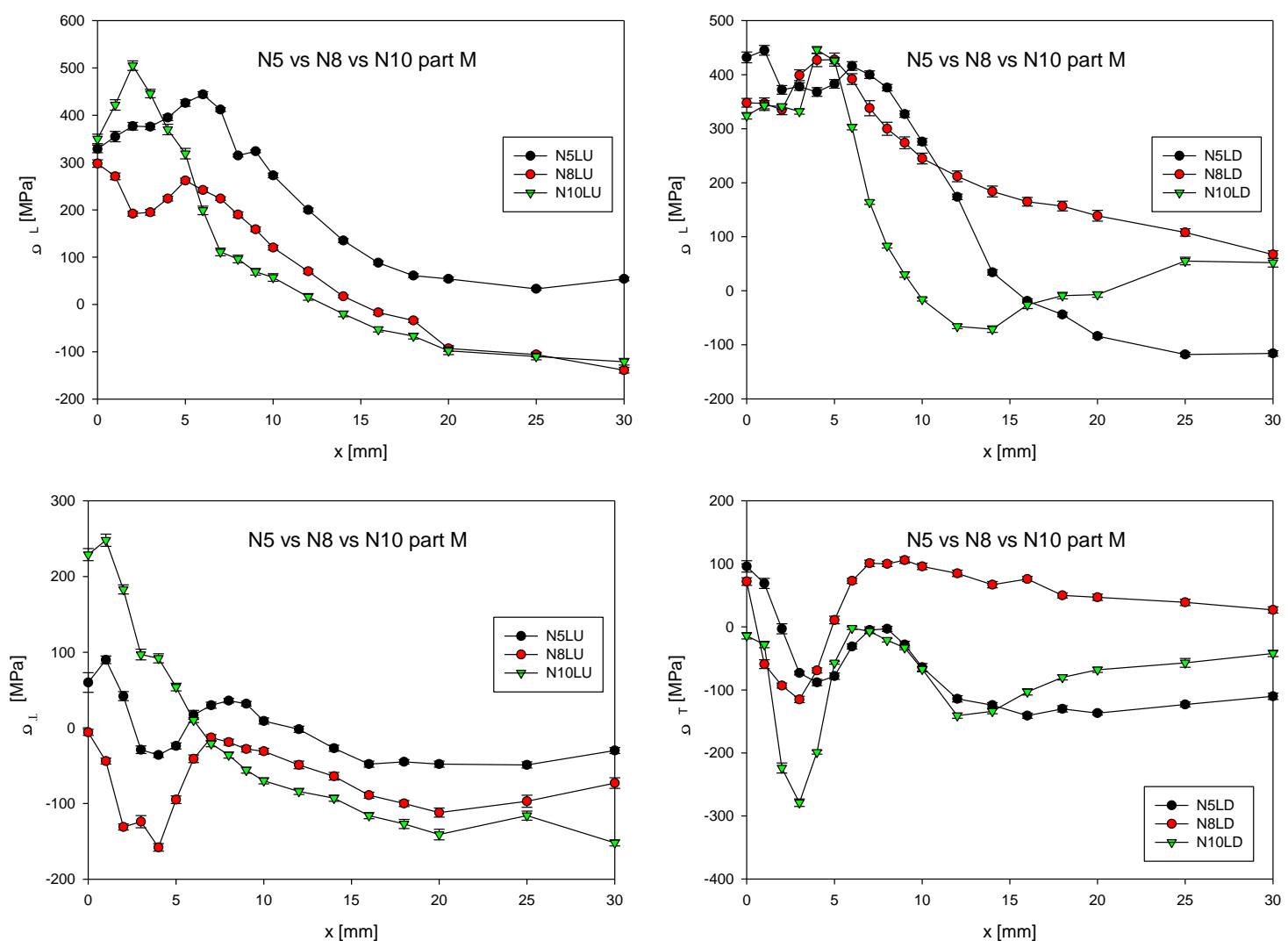

Figure 4. Surface residual stresses in relation to thickness of the samples; $x$ stands for distance from the weld's centre

\subsection{Influence of analysed side of the plate}

Values of RS of bulk material are different because of rolling of the plates or shrinkage after welding, see Figs. 5. Moreover, higher RS were analysed on the last welded side. Therefore, for single-sided weld (sample N5), the higher RS are on the side U. On the other hand, using double-sided welding, the values of $R S$ on the side $U$ decrease (because the side $D$ was welded as the second one). Generally, there are differences between single- and doublesided welding. The biggest effect of double-sided welding is evident for N10L sample in the direction T, where tensile RS are generated in the HAZ. 

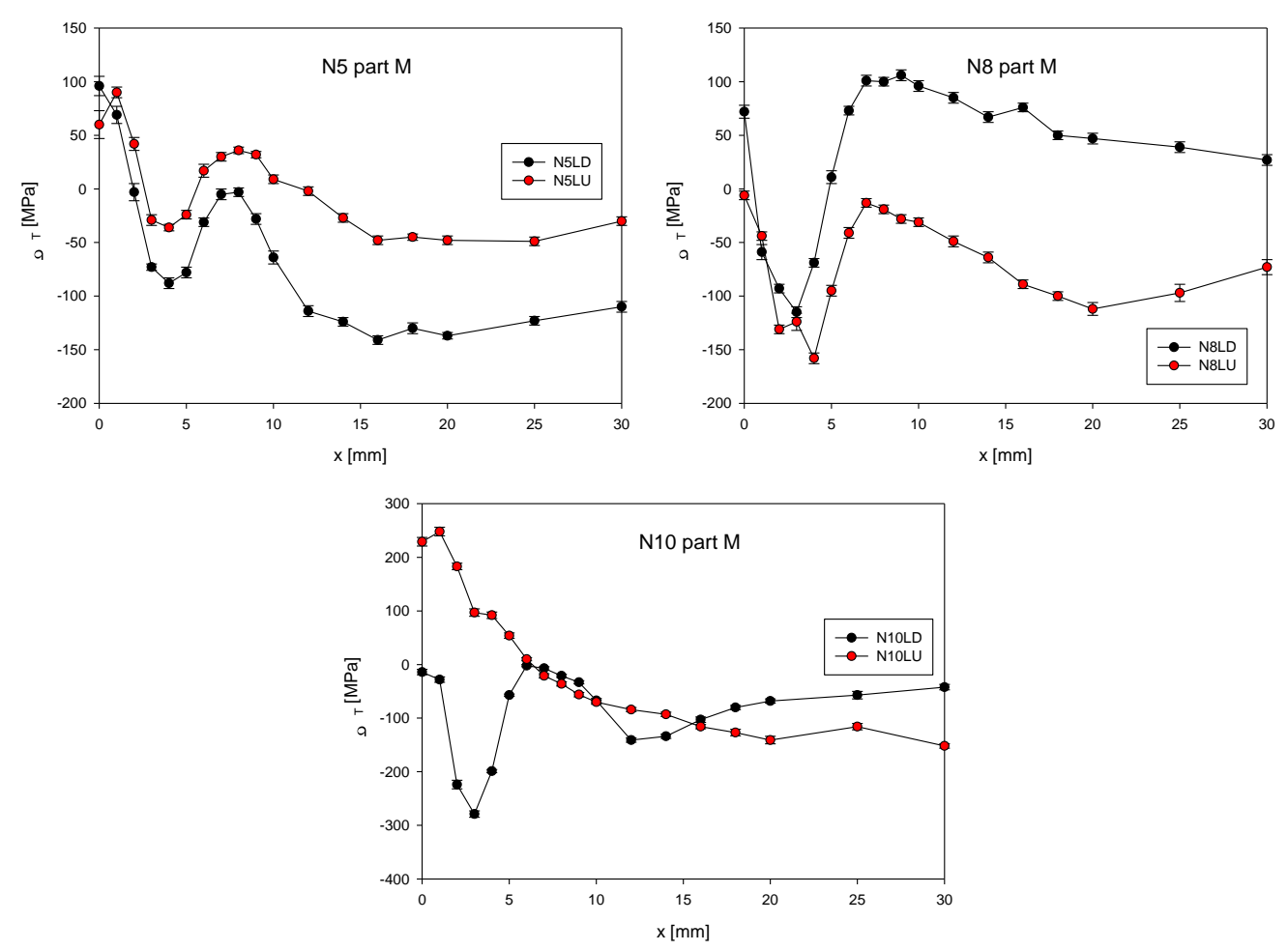

Figure 5. Surface residual stresses in relation to analysed side of the samples; $x$ stands for distance from the weld's centre

\section{CONCLUSIONS}

From experimental results, it can be stated as follows:

- The initial (bulk) state of residual stresses (RS) is affected either by shrinkage of material after welding or by rolling of plates.

- $\quad$ The trends of RS do not depend on analysed area S, M, or F, see Fig. 2.

- The tensile residual stresses are higher in the direction of welding (L).

- With increasing thickness of samples, the size of heat affected zone decreases by 2-3 $\mathrm{mm}$ and stress affected zone by $1-2 \mathrm{~mm}$.

- For single-sided weld (sample N5), the higher RS are on the upper (U) side. Using double-side welding, the values of residual stresses on the side $U$ decrease.

\section{ACKNOWLEDGMENTS}

This research was carried out in the frame of the research projects TH02010664 of the Technology Agency of the Czech Republic.

\section{REFERENCES}

[1] Totten G. E., Howes M. \& Inoue T. (2002). Handbook of residual stress and deformation of steel. Materials Park: ASM International.

[2] Černý I. \& Sís J. (2016). Evaluation of Fatigue Strength of Different Thickness Laser Welded S355 Steel Sheets Considering Microstructure, Surface Conditions and Residual Stresses. Key Engineering Materials, Vol. 713, pp. 82-85.

[3] Nitschke-Pagel T. \& Digler K. (2014). Sources and Consequences of Residual Stresses due to Welding. Materials science forum, Vol. 783-786, pp. 2777-2785.

IRTIIE Vol. 5, No. 3, 2017 ISSN 1314-8788 (print), ISSN 1314-8796 (online), doi: 10.15547/artte.2017.03.004 